\title{
SAÚDE E AMBIENTE NOS TRILHOS DO CUIDADO: CONCEPÇÕES E CONEXÕES
}

\author{
Crystiane Ribas Batista Ribeiro', Vera Maria Saboia', Lina Márcia Miguéis Berardinelli², \\ Marcela de Abreu Moniz ${ }^{1}$, Eliane Ramos Pereira' ${ }^{1}$ e Tatiane Marinz de Souza Luquez ${ }^{1}$
}

\author{
1Universidade Federal Fluminense, Brasil, crystiane.ribas@gmail.com; versaboia@uol.com.br; \\ marceladeabreumoniz@gmail.com; elianeramos.uff@gmail.com; tatianemarinz@yahoo.com.br \\ ²Universidade do Estado do Rio de Janeiro, Brasil, linamigberardinelli@gmail.com
}

\begin{abstract}
Resumo. Introdução: Utilizando-se o conceito ampliado de saúde, a determinação do ambiente sobre ela e o cuidado como condutor da relação entre ambos, importa analisar concepções sobre ambiente e saúde de estudantes de uma escola pública no entorno de uma comunidade pesqueira exposta ao incremento da degradação ambiental, visando à promoção de práticas educativas em saúde por enfermeiros. Objetivo: Analisar a relação entre ambiente e saúde na visão de estudantes, tendo em vista a tridimensionalidade do cuidado, fundamentada em Leonardo Boff. Métodos: Estudo qualitativo, com abordagem participativa, do tipo estudo de caso. Participaram do estudo 24 estudantes do $6^{\circ}$ ano do ensino fundamental. Como técnica de produção de dados foi utilizada a entrevista semiestruturada. Para análise dos dados optou-se pela Análise de Conteúdo de Bardin com auxílio do software Atlas.ti. Resultados: Emergiram duas categorias de análise Ambiente: concepções dos estudantes; e Ambiente que gera saúde e ambiente que gera doença. Conclusões: Questões ambientais não se esgotam na preservação e conservação da natureza. Promover reorientações nas questões socioambientais e de saúde suscitam um outro perfil do enfermeiro educador, comprometido não apenas com o cuidado do ser humano, mas com a transformação da relação homem/ambiente a partir do cuidado tridimensional.
\end{abstract}

Palavras-chave: Educação em Saúde; Educação Ambiental; Poluição Ambiental; Ensino Fundamental e Médio; Enfermagem.

\section{HEALTH AND THE ENVIRONMENT ON THE TRAILS OF CARE: CONCEPTIONS AND CONNECTIONS}

\begin{abstract}
Introduction: Using the expanded concept of health, the determination of the environment over it and care as the driver of the relationship between them, it is important to analyse conceptions about the environment and health of students at a public school in the vicinity of a fishing community exposed to the increase of environmental degradation, aiming at the promotion of educational health practices by nurses. Objectives: To analyse the relationship between environment and health in the view of students, in view of the three-dimensionality of care, based on Leonardo Boff. Methods: Qualitative study, with a participatory approach, of the case study type. 24 students from the 6th year of elementary school participated in the study. As a data production technique, semi-structured interviews were used. For data analysis, Bardin Content Analysis was chosen with the aid of the Atlas.ti software. Results: Two categories of analysis emerged Environment: students' conceptions; and Environment that generates health and environment that generates disease. Conclusions: Environmental issues are not limited to the preservation and conservation of nature. Promoting reorientations in socioenvironmental and health issues raise another profile of nurse educators, committed not only to the care of human beings, but with the transformation of the human / environment relationship based on three-dimensional care.
\end{abstract}

Keywords: Health Education; Environmental Education; Environment Pollution; Elementary and High School; Nursing.

\section{INTRODUÇÃO}

Consonante ao conceito ampliado de saúde e a determinação do ambiente sobre ela tornase imprescindível ao enfermeiro inserido na educação básica, como integrante do Programa 
Saúde na Escola (PSE), pensar em estratégias que possam alicerçar práticas educativas em saúde que promovam a conexão entre homem/ambiente.

Pesquisar sobre a atual circunstância socioambiental da sociedade é suscitar a reflexão sobre a relação homem-homem intrínseca na relação homem-mundo. Segundo Freire (2016), tal relação revela-se pela consciência do homem acerca do domínio do ponto de decisão de sua busca em si e em suas relações com o mundo, e com os outros, impregnando o mundo de sua presença criadora e transformadora, não somente vivendo, mas existindo numa relação dialética entre os condicionamentos e sua liberdade.

$\mathrm{Na}$ relação homem-mundo, tem-se o cuidado como garantia para a sobrevivência das espécies, um comportamento inato do ser humano para preservação do mundo. A conjugação da natureza e a forma de condução da vida permite, tanto aos seres humanos como aos demais seres vivos, buscarem a continuidade de suas espécies e um legado na história do universo (Galdrón, 2012).

Pensando na atual fase planetária, permeada por uma crise ambiental profunda, exige-se um discurso ético universal consolidado em algo que pertença à essência concreta do ser humano e que, portanto, possa ser achado e desenvolvido a partir da práxis educativa, $o$ cuidado.

O conceito outrora arraigado e restrito à esfera biológica de cuidado, fragmentado na abordagem do processo saúde-adoecimento com vistas à cura de doenças, amplia-se ao longo da história. Há necessidade de apropriação de instrumentos que possibilitem relações terapêuticas humanas, competentes e produtoras de autonomia aos participantes da relação de cuidado (Boff, 2013).

Cuidar é mais que um ato, é uma atitude. Portanto, abrange mais que um momento de atenção, de zelo e de desvelo. Representa uma atitude de ocupação, preocupação, de responsabilização e de envolvimento afetivo com o outro (Boff, 2014). Uma aliança de cuidado para com a vida humana, toda comunidade de vida e a Terra deve ser mediante a sustentabilidade real, verdadeira, efetiva e global, conjugada com o princípio do cuidado (Boff, 2015).

A visão do cuidado é a de que o cidadão está sempre envolvido numa trama de conexões. O cuidado como dimensão ontológica e antropológica mostra clara vinculação de todos com 
todos devido à reciprocidade geral e à lógica do cuidar e do ser cuidado, assumida como compromisso relacional (Boff, 2013).

Considera-se a importância de que cada um encontre a essência do cuidado dentro de si a fim de que haja de maneira congruente o estabelecimento coordenado das três dimensões do cuidado apreendidas e vivenciadas: o cuidado de si mesmo, o cuidado do outro e o cuidado do ambiente.

Entende-se, portanto, que o cuidado tridimensional ancorado nos preceitos de Leonardo Boff, necessita de uma construção sequencial e gradativa no âmbito do processo de ensinoaprendizagem. Partindo desse prisma, o indivíduo estará apto a apreender o cuidado ambiental, após a conscientização do cuidado do eu e do cuidado do outro. Nesse sentido, o objetivo desse estudo foi analisar a relação entre ambiente e saúde na visão de estudantes, tendo a tridimensionalidade do cuidado fundamentada em Leonardo Boff como eixo condutor.

\section{METODOLOGIA}

Trata-se de um estudo de natureza qualitativa, com abordagem participativa, do tipo estudo de caso. A pesquisa foi realizada no Colégio Estadual Coronel Francisco Lima, próximo à colônia de pescadores do Gradim, no município de São Gonçalo, RJ, no mês de abril de 2018. O critério para a escolha da referida escola se deu pela proximidade com a comunidade pesqueira da colônia Z-08, que vivenciam atualmente acentuado declínio socioeconômico atribuído principalmente à poluição ambiental da Baía de Guanabara. Tal localidade vivencia sobreposição de cargas ambientais de fatores de risco conforme descrito em estudos anteriores (Ribeiro, 2011; Ribeiro, Saboia, \& Souza, 2013).

Definiram-se como critérios de inclusão dos participantes da pesquisa: estudantes que estivessem cursando o 6ำ ano do ensino fundamental do Colégio Estadual Coronel Francisco Lima no município de São Gonçalo, que residiam na comunidade pesqueira ou adjacências e tivessem algum vínculo com esta localidade, como por exemplo, pai, avô e/ou tio pescadores atualmente ou que já tenham sido pescadores em um dado momento da vida. Os critérios de exclusão dos educandos foram: estudantes que não estivessem com a matrícula ativa ou que estivessem de licença médica no período de realização da pesquisa. 
Para produção dos dados, adotou-se a entrevista semiestruturada, que transcorreu a partir de um roteiro com duração média de 6 minutos, sendo gravada a partir da prévia explicação ao estudante. O roteiro foi desenvolvido considerando os tópicos centrais saúde, ambiente e a relação entre saúde e ambiente considerando aspectos socioambientais locais e direcionando para questões balizadas pelo cuidado de si, do outro e do ambiente. Para análise e interpretação dos dados optou-se pela Técnica de Análise de Conteúdo proposta por Bardin (2010), implementada com o auxílio do software ATLAS.ti.

Primeiramente foi realizada a pré-análise, dando origem à constituição do corpus da pesquisa, por meio da organização do material a ser analisado, tornando-o operacional. Os documentos primários (P-Docs), obtidos a partir das entrevistas foram devidamente agrupados no software. As falas dos estudantes sofreram sucessivas leituras até serem feitos os recortes de textos dos documentos em análise, as citações (Quotes).

$\mathrm{Na}$ exploração do material foi feito o exame minucioso do material para a definição de categorias (sistemas de codificação) e a identificação das unidades de registro (unidade de significação a codificar, corresponde ao segmento de conteúdo a considerar unidade-base, visando à categorização e à frequência) e de contexto (unidade de compreensão para codificar a unidade de registro que corresponde ao segmento da mensagem, a fim de compreender a significação exata dela) nos documentos. As citações foram sendo inseridas em seus respectivos códigos (Codes). Dessa forma, foram feitas a codificação, a classificação e a categorização dos elementos (Bardin, 2010).

Esses elementos deram origem aos networks, redes ou teias, (ferramentas de análise utilizadas para ilustrar as relações que foram analisadas pelo pesquisador) conferindo informações para análise, o que resultou nas interpretações inferenciais. Momento de intuição, de análise reflexiva e crítica.

O referencial teórico-metodológico que norteou a interpretação dos dados foi o cuidado tridimensional (o cuidado de si, o cuidado do outro, o cuidado ambiental) fundamentado em Leonardo Boff, tendo em vista a lógica da natureza e da vida humana fundadas sobre a cooperação e a interdependência entre todos, assim como aspectos da saúde em interdependência com aspectos ambientais.

A pesquisa foi aprovada pelo Comitê de Ética do Hospital Universitário Antônio Pedro sob o CCAE no 64847517.9 .0000 .5243 , tendo a assinatura da carta de anuência e dos Termos de 
Consentimento Livre e Esclarecido (TCLE) e o de Assentimento Livre e Esclarecido (TALE), respectivamente pela direção da instituição, pais e estudantes. A fim de se preservar o anonimato dos participantes e facilitar futuras análises, cada estudante foi identificado nos materiais obtidos pela inicial da palavra estudante $(E)$ seguida do número correspondente ao total de estudantes participantes, seguindo-se (E1, E2, E3, ... E24).

\title{
3. RESULTADOS
}

Participaram um total de 24 estudantes com idades de 11 a 14 anos, sendo 13 meninos e 11 meninas. A partir da análise das entrevistas com o auxílio do ATLAS.ti., emergiram duas categorias: Ambiente: concepções dos estudantes; e Ambiente que gera saúde e ambiente que gera doença.

\subsection{Ambiente: concepções dos estudantes}

Conforme as falas a seguir, a concepção de meio ambiente revela o caráter naturalista da percepção ambiental e diz respeito a um local preservado, intangível e distante da realidade vivida:

\author{
"A natureza pra mim é o meio ambiente". E1 \\ “Animais, floresta, árvores, ...”. E3 \\ "A natureza, um lugar limpo". E16
}

$\mathrm{Na}$ concepção naturalista, o meio ambiente é visto como restrito à natureza que deve ser apreciada, respeitada e preservada (Reigota, 1991; Sauvé, 1996). De acordo com Loureiro, Layrargues e Castro (2012), o naturalismo é uma das posturas típicas no tratamento da problemática ambiental, em cujo contexto os problemas são abordados em sentido ahistórico, ignorando as relações sociais e onde a relação homem/ambiente é condicionada às relações naturais e à sua dinâmica.

Para Freire (2016), o mundo humano, sendo histórico, permite ao homem assumir a vida, sendo capaz de construí-la. Não considerar as relações sociais e sua articulação com o meio ambiente fortalece a dicotomização homem/ambiente.

Estudos realizados têm mostrado a prevalência da visão dicotomizada por estudantes do ensino fundamental (Pedrini, Costa, \& Ghilardi, 2010; Silva, 2013; Luz, Prudêncio, \& Caiafa, 2018), o que pode estar associado com a forma como o tema tem sido abordado nas escolas. Apesar de ser proposto pelos Parâmetros Curriculares Nacionais (PCN) como tema transversal, permeando todas as disciplinas curriculares e a Política Nacional de Educação 
Ambiental (PNEA) ser clara e incisiva quanto à obrigatoriedade da educação ambiental nas escolas tanto na educação básica quanto na educação superior.

Como ainda reafirma Castro e Marcano (2013), a solução dos problemas para a qualidade de vida e melhoramento ambiental, desde local ao planetário, é avaliar e repensar o currículo escolar de forma que se consolide uma formação sólida em relação à educação ambiental capaz de formar cidadãos que desenvolvam habilidades e atitudes na relação homem/ambiente.

A fala seguinte revela a contradição vivenciada pelos estudantes:
"Meio ambiente é... lugares onde ficam plantas, bichos e hoje em dia a gente não vê isso né? Hoje a gente não vê geralmente muitos bichos. O que a gente vê nos livros é... bichos, é... tipo que limpo, mas geralmente a gente não vê isso, a gente vê sujeira, não vê bicho direito". E7

Os livros apresentam um ambiente limpo e repleto de elementos naturais que parecem não interagir com o homem, mas no entorno em que vivem se deparam com um ambiente poluído, destoante dos livros e do que aprendem em sala de aula.

Tal contradição pode relacionar-se com o que Freire descreve como "tema gerador", uma vez que se trata de um problema revelado nas contradições presentes, na estrutura e organização social.

Segundo Reigota (1991) e Sauvé (1996), na concepção globalizante podem-se perceber relações recíprocas entre natureza e sociedade, evidenciando aspectos biofísicos, sociais, políticos e culturais. Nesse tipo de concepção, o homem é inserido como parte integrante do meio, há real noção de pertencimento como denotam as falas (E8, E12, E13 e E18):

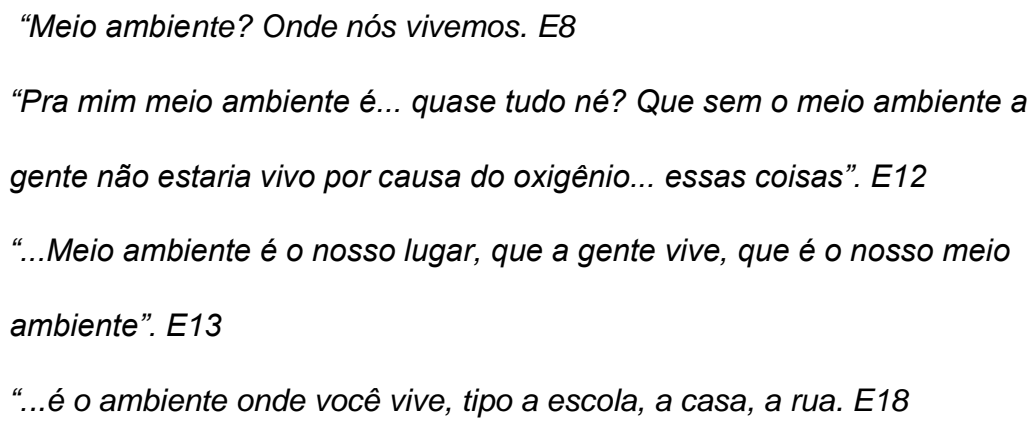

A aproximação homem/ambiente, é fundamental para que, como ressaltam Rodrigues e Junior (2009), a ideologia individualista atrelada a cultura industrial capitalista moderna que construiu uma representação mecânica do ser humano e que diminuiu sua capacidade de 
se relacionar com o outro (social) e com o mundo (ambiental) seja aos poucos substituída, permitindo ao homem compreender a práxis de seu potencial transformador.

No momento em que os indivíduos, atuando e refletindo, são capazes de perceber a estrutura em que se encontram, entendem a realidade como realmente é: uma realidade histórico-cultural criada pelos homens e que pode ser transformada por eles (Freire, 2014).

É possível observar pela fala dos participantes que a educação é a chave para a mudança do cenário ambiental. Reconhece-se que o conhecimento é parte do processo e que educação ambiental factível depende não somente da ação governamental, mas de uma ação coletiva que supere a concepção moralista e o individualismo.

Numa leitura mais ampliada do contexto, os estudantes são capazes de identificar as verdadeiras potencialidades deste, por meio da solução dos problemas reais aos quais estão submetidos. É importante fomentar a consciência do que implica a celebração do Dia da Água, por mecanismos de manejo e uso eficiente do líquido, da importância da conservação do recurso como fonte que se esgota para torná-lo um uso sustentável (Mejía, Marin, \& Lopes, 2015).

A educação ambiental permite ao educando desvendar os elos da cadeia de poder nas questões ambientais e a dinâmica da relação entre sociedade, Estado, economia, saúde e meio ambiente.

\subsection{Ambiente que gera saúde e ambiente que gera doença}

$\mathrm{Na}$ concepção dos participantes do estudo, a saúde é compreendida para além da visão biologicista, restrita à ausência de doenças, que admite que ser saudável só o é quando se tem a integridade de suas funções biológicas.

Todavia, há falas que demonstram a persistência dessa concepção como a fala seguinte:

"Saúde é ter uma estrutura boa. Não aparentar ser doente. Não viver ferido, se ficar doente se cuida”. E8

Para Almeida Filho (2011), numa crítica à teoria funcionalista de Christopher Boorse, saúde pode ser entendida como eficiência funcional; enquanto doença ou patologia se define por falha ou déficit de função, 'ausência de normalidade'. Para o autor, contudo, a antinomia saúde-doença é algo herdado do modelo biomédico tradicional, que precisa ser superado. 
Os estudantes associam saúde à alimentação adequada, além de outras atitudes e comportamentos, como: ingestão hídrica adequada, não consumir álcool, se expor ao sol com proteção, não fumar, realizar exames periodicamente, praticar atividade física, que são ações de autocuidado.

Em algumas falas, é possível evidenciar a influência do ambiente na saúde:

“... Porque não basta ficar comendo coisas saudáveis e fazer exercícios, tem que ter o ar limpo, o ambiente limpo. Você tá, fazendo um piquenique, às vezes não pode porque tá tudo sujo. Aí quando o ambiente tá limpo você pode ficar ali, se divertindo alegremente. E não ficar na sujeira, sentindo o cheiro daquilo...”. E22

A saúde deve envolver a complexidade das relações entre o indivíduo e o meio ambiente. A vida em contato com a natureza tem um conjunto de benefícios para a saúde humana, física e mental, além de representar mais uma possibilidade de aproximação entre esta e o indivíduo, devido à interação com os elementos naturais e as suas variações, promovendo assim o respeito pelo meio ambiente (Rodrigues \& Darido, 2006; Sandell \& Öohman, 2010).

Em consonância, autores afirmam que o conceito de saúde reflete a conjuntura social, econômica, política e cultural. Saúde não representa a mesma coisa para todas as pessoas. Dependerá de valores individuais, concepções científicas, religiosas e filosóficas (Scliar, 2007; Quandt et al., 2014).

O ambiente poluído foi atrelado às doenças transmitidas por vetores, possivelmente, doenças prevalentes na comunidade em estudo devido à aproximação com o rio e quantidade excessiva de lixo doméstico, lançado nas ruas e quintais das moradias. $O$ depoimento a seguir corrobora com essa visão:

"Tem, tem a ver com saúde... Jogar lixo na rua, uma coisa assim, aí uma pessoa passa, aí vem os pombos e urubus, aí polui tudo lá e fica sujo... aí uma pessoa pode ficar doente por causa dos mosquitos também". E5

Quando questionados sobre a relação entre saúde e ambiente, alguns participantes relacionaram a poluição ambiental com a redução da quantidade de alimentos disponíveis, interferindo na nutrição humana e, consequentemente, na sua saúde. Outros estudantes relacionaram saúde e ambiente com a capacidade fotossintética que ao declinarem em número de espécies, em decorrência da poluição ambiental, poderiam afetar a saúde humana e o clima: 
"Sim, porque os vegetais fazem parte do meio ambiente, não fazem? Então... pra botar na comida os vegetais, essas coisas". E1

"É... pra mim tem... por causa da vegetação, das plantações essas coisas, um exemplo, tá cheio de poluição, petróleo essas coisas e a vegetação é a que faz a fotossintese, ajuda a mudar o clima”. E3

O ambiente ora visto por alguns estudantes como potencial gerador de doenças é descrito por outros como ambiente que gera a vida, pois é a partir dele que o ser humano obtém alimentos que irão compor sua matéria orgânica e, a partir dele, tem disponível o oxigênio para respiração, como evidenciado nas falas seguintes:

\footnotetext{
"Tem a ver, porque da sujeira que nós fizermos, pode afetar nossa saúde, como botar fogo em pneu, vai poluir o ar, pode acabar com o oxigênio que temos". E8

"Pra mim tem... a saúde a gente cuida com algumas coisas que tem no ambiente. Tipo, pra ser saudável algumas vezes tem que comer frutas, legumes, alimentos pra gente ficar saudável, que são do meio ambiente". E12
}

O cuidado ambiental vai muito além da sustentabilidade disseminada na sociedade, que prioriza a preocupação em cumprir normas e diretrizes que concederão a garantia de recursos naturais para as gerações futuras usufruírem, é uma questão de vida. O ser humano é composto pelo que há no ambiente, por conseguinte, o ambiente é parte do ser humano.

A concepção de sustentabilidade não pode ser reducionista e aplicar-se apenas ao crescimento/desenvolvimento. A sustentabilidade envolve a sociedade, a educação, a política, a cultura, a arte, a natureza, o planeta e a vida de cada pessoa (Boff, 2015).

Estudo destaca a importância das parcerias entre educação, saúde e ambiente no contexto escolar, pois fortalecem a construção de uma postura protagonista do educando no cuidado ao ambiente em que vive (Lima \& Miranda, 2015).

Entretanto, não um cuidado alienado, fundamentado no ativismo, ação sem reflexão, mas que mediatizado pela educação problematizadora leva o estudante a compreender que o ambiente é um determinante da saúde e mais do que isso, que há agentes produtores do modelo modernizante, de forma contundente, com que se tem acerbado a já forte segregação socioespacial das periferias, onde às dificuldades socioeconômicas decorrentes 
dos salários baixos se aliam aos males que vêm com a poluição, com a precariedade dos serviços de saúde e com a falta de instalações públicas adequadas e de equipamentos culturais (Silva \& Rainha, 2013).

\section{CONCLUSÕES}

Entre os estudantes participantes do estudo observou-se o predomínio da concepção naturalista sobre ambiente, reforçando a necessidade da educação ambiental nos currículos escolares como atividade nuclear, a fim de evitar contradições entre o ambiente apresentado nos livros didáticos e o contexto do aluno.

Quanto à concepção de saúde, houve predomínio da visão fundamentalmente associada aos comportamentos e atitudes, como alimentação adequada e prática de atividade física. $\mathrm{O}$ ambiente foi associado à saúde como fonte de alimentos e fornecedor de oxigênio para a respiração dos seres vivos.

A metodologia qualitativa de investigação permitiu o aprofundamento do universo de significados construídos pelo estudante acerca da saúde, do ambiente e a da relação entre ambos viabilizando futuras práticas educativas em saúde que façam sentido como parte da sua realidade social.

A pesquisa revelou a importância de se promover uma articulação entre saúde e ambiente, a partir do cuidado tridimensional, com vistas à construção de novos saberes que possam consolidar a elaboração de práticas educativas em saúde que sejam aplicadas em contextos semelhantes aos da comunidade pesqueira em tela. Ressaltando a noção de pertencimento e a possibilidade de despertamento do cuidado como essência humana, a partir de uma consciência crítica e social mais profunda, para que o estudante possa compreender as diferentes dimensões da questão ambiental.

É fato que as questões ambientais não se esgotam na preservação e conservação da natureza. Portanto, promover reorientações nas questões socioambientais e de saúde suscitam um outro perfil do enfermeiro educador, comprometido não apenas com o cuidado do ser humano, mas com a transformação da relação homem/ambiente a partir do cuidado tridimensional.

Agradecimentos. Aos estudantes do $6^{\circ}$ ano do Colégio Estadual Coronel Francisco Lima - SG, RJ. 


\section{REFERÊNCIAS}

Almeida Filho, N. (2011). O que é saúde? Rio de Janeiro: Editora Fiocruz.

Bardin, L. (2010). Análise de conteúdo. Lisboa: Edições 70.

Boff, L. (2013). Saber cuidar: ética do humano, compaixão pela terra. Petrópolis: Vozes.

Boff, L. (2014). O cuidado necessário. Petrópolis: Vozes.

Boff, L. (2015). Sustentabilidade: o que é - o que não é. Petrópolis: Vozes.

Freire, P. (2014). Educação e mudança. São Paulo: Paz e Terra.

Freire, P. (2016). Pedagogia do oprimido. Rio de Janeiro: Paz e Terra.

Castro, J. A. T., \& Marcano, N. (2013). Propuesta de innovación educativa mediante el uso de las TIC para la promoción de valores ambientales em la educación primaria venezolana. Revista de investigación, 37(79), 33-48.

Gualdrón, L. M. V. ( 2012). Evolução do cuidado: de curanderas a enfermeras. Revista Cuidarte, 3(1), 410-415.

Lima, S. M. P., \& Miranda, M. H. R. (2015). Prática docente, pesquisa e iniciação científica: um olhar para questões ambientais na escola pública. Revista Ambivalências, 3(6), 237- 254.

Loureiro, C. F. B., Layrargues, P. P., \& Castro, R. S. de (orgs.). (2012). Sociedade e meio ambiente: a Educação Ambiental em debate. São Paulo: Cortez.

Luz, R., Prudêncio, C. A.V ., \& Caiafa, A. N. (2018). Contribuições da educação ambiental crítica para o processo de ensino aprendizagem em ciências visando à formação cidadã. Investigações em Ensino de Ciências, 23(3), 60-81.

Mejía, A. M. B., Marín, L. B. M., \& López, L. M. R. (2015). Incidencia de los processos educomunicativos em los proyectos ambientales escolares. Revista Lasallista de Investigación, 12(2), 75-83.

Pedrini, A., Costa, E. A., \& Ghilardi, N. (2010). Percepção ambiental de crianças e pré-adolescentes em vulnerabilidade social para projetos de educação ambiental. Ciência \& Educação, 16(1), 163-179.

Quandt, F. L et al. (2014). Saúde Ambiental e atenção à saúde: construção e ressignificação de referências. Cadernos de Saúde Coletiva, 22(2), 150-157.

Reigota, M. (1991). O MA e suas representações no ensino em São Paulo, Brasil. Uniambiente, 2(1), 27-30.

Ribeiro, C. R. B. (2011). A influência dos rios do município de São Gonçalo sobra a qualidade das águas da Baía de Guanabara-RJ. Monografia (Graduação em Ciências Biológicas) - Faculdade de Formação de Professores, Universidade do Estado do Rio de Janeiro, Rio de Janeiro.

Ribeiro, C. R. B., Saboia, V. M., \& Souza, D. K. (2015). Environmental impact, work and health of artisanal fishermen: popular education in focus. Revista de pesquisa cuidado é fundamental, 7(3), 2835-2845.

Rodrigues, C., \& Junior, L. (2009). Ecomotricidade: sinergia entre educação ambiental, motricidade humana e pedagogia dialógica. Motriz, 15(4), 987- 995.

Rodrigues, L., \& Darido, S. (2006). Educação Física escolar e meio ambiente: reflexões e aplicações pedagógicas. Educación Física y Deportes, 100.

Sandell, K., \& Öohman, J. (2010). Educational potentials of encounters with nature: reflections from a Swedish outdoor perspective. Environmental Education Research, 16(1), 113-132.

Sauvé, L. (1996). Environmental Education and Sustainable Development: A Further Appraisal. In Paper presented to the Canadian Journal of Environmental Education, 1(1), 7-34.

Scliar, M. (2007). História do conceito de saúde. Physis: Revista de Saúde Coletiva, 17(1), 29-41.

Silva, C. A., \& Rainha, F. A. (2013). Metodologia de Ensino de Educação Ambiental em Escola Situada na Área Costeira da Baía de Guanabara. Revista da Gestão Costeira Integrada, 13(2), 181-192. 